\title{
Signaling pathways involved in vascular smooth muscle cell calcification during hyperphosphatemia
}

\author{
Jakob VoelkI ${ }^{1,2,3,4} \cdot$ Florian Lang $^{5} \cdot$ Kai-Uwe Eckardt $^{4} \cdot$ Kerstin Amann $^{6} \cdot$ Makoto Kuro-o $^{7} \cdot$ Andreas Pasch $^{8}$. \\ Burkert Pieske $^{2,3,9,10} \cdot$ loana Alesutan ${ }^{1,2,3,9}$
}

Received: 30 September 2018 / Revised: 13 February 2019 / Accepted: 21 February 2019 / Published online: 18 March 2019

(c) The Author(s) 2019

\begin{abstract}
Medial vascular calcification has emerged as a putative key factor contributing to the excessive cardiovascular mortality of patients with chronic kidney disease (CKD). Hyperphosphatemia is considered a decisive determinant of vascular calcification in CKD. A critical role in initiation and progression of vascular calcification during elevated phosphate conditions is attributed to vascular smooth muscle cells (VSMCs), which are able to change their phenotype into osteo-/chondroblastslike cells. These transdifferentiated VSMCs actively promote calcification in the medial layer of the arteries by producing a local pro-calcifying environment as well as nidus sites for precipitation of calcium and phosphate and growth of calcium phosphate crystals. Elevated extracellular phosphate induces osteo-/chondrogenic transdifferentiation of VSMCs through complex intracellular signaling pathways, which are still incompletely understood. The present review addresses critical intracellular pathways controlling osteo-/chondrogenic transdifferentiation of VSMCs and, thus, vascular calcification during hyperphosphatemia. Elucidating these pathways holds a significant promise to open novel therapeutic opportunities counteracting the progression of vascular calcification in CKD.
\end{abstract}

Keywords Osteogenic signaling $\cdot$ Vascular smooth muscle cells $\cdot$ Vascular calcification $\cdot$ Phosphate $\cdot$ CKD

\section{Introduction}

Medial vascular calcification, often termed in short vascular calcification, represents the pathological deposition of calcium and phosphate in the medial layer of the arteries [1]. Vascular calcification is observed as a common complication

Jakob Voelkl

jakob.voelk1@jku.at

1 Institute for Physiology and Pathophysiology, Johannes Kepler University Linz, Altenberger Strasse 69, 4040 Linz, Austria

2 Department of Internal Medicine and Cardiology, CharitéUniversitätsmedizin Berlin, Campus Virchow-Klinikum, Augustenburgerplatz 1, 13353 Berlin, Germany

3 DZHK (German Centre for Cardiovascular Research), Partner Site Berlin, 13347 Berlin, Germany

4 Department of Nephrology and Medical Intensive Care, Charité-Universitätsmedizin Berlin, Augustenburgerplatz 1, 13353 Berlin, Germany

5 Department of Physiology I, Eberhard-Karls University, Wilhelmstr. 56, 72076 Tübingen, Germany in chronic kidney disease (CKD) [2,3], diabetes mellitus [4], and aging [5]. It is also found in association with various pathological conditions including hypertension, atherosclerosis, osteoporosis, and rheumatoid arthritis [6,7], and can be caused by rare monogenic disorders $[8,9]$.

6 Department of Nephropathology, Universität Erlangen-Nürnberg, Krankenhausstr. 8-10, 91054 Erlangen, Germany

7 Center for Molecular Medicine, Jichi Medical University, 3311-1 Yakushiji, Shimotsuke, Tochigi 329-0498, Japan

8 Calciscon AG, Aarbergstrasse 5, 2560 Nidau-Biel, Switzerland

9 Berlin Institute of Health (BIH), Anna-Louisa-Karsch Str. 2, 10178 Berlin, Germany

10 Department of Internal Medicine and Cardiology, German Heart Center Berlin (DHZB), Augustenburger Platz 1, 13353 Berlin, Germany 
The most extensive vascular calcification is observed in patients with CKD $[2,3]$. In these patients, vascular calcification was suggested as a critical risk factor for cardiovascular events, and is associated with increased cardiovascular and all-cause morbidity and mortality $[10,11]$. Vascular calcification has been considered decisive for the clinical course of the disease [2]. Nonetheless, the exact contribution of vascular calcification to cardiovascular mortality remains to be established, as currently only observational data are available. The observational studies are hampered by the slow onset and progression of vascular calcification and limited diagnostic methods. The recent discovery of a nanoparticle-based test of the calcification propensity may, however, establish a clinical approach to study risk factors and mechanisms of vascular calcification in CKD [12].

However, so far, the complex processes leading to vascular calcification in CKD remain incompletely understood. Consequently, no convincing concepts and treatment options to prevent or reduce the development of vascular calcification are yet available $[13,14]$.

\section{Phosphate and vascular calcification in CKD}

In CKD, the initiation and progression of vascular calcification is triggered by a combination of various pathological factors $[2,3,15,16]$. Dysregulation of mineral homeostasis and elevated phosphate levels are considered key determinants of vascular calcification in CKD $[1,17]$. Hyperphosphatemia frequently occurs as a consequence of impaired renal function [2] and is associated with vascular calcification $[2,6]$ as well as increased risk for cardiovascular events and death [18]. However, the effects of phosphate binders on vascular calcification are still uncertain [19], which may be also attributed to the complex interplay of systemic phosphate handling and the availability of bone as a large source of phosphate [20]. Phosphate handling and development of hyperphosphatemia in CKD have been reviewed in detail elsewhere [20-24].

Phosphate complexes with calcium and calcium phosphate nanoparticles are able to activate pro-calcific intracellular signaling pathways $[25,26]$. Increased calcium phosphate product levels [27] and calcium phosphate-protein complexes, known as calciprotein particles (CPPs) [28-30], are associated with the development of vascular calcification in CKD. The formation of CPPs and mineral stress have been reviewed in detail elsewhere [31, 32].

Even in patients with normal renal function, enhanced serum phosphate levels are associated with coronary artery calcification [33] and a high risk of cardiovascular events and mortality [34]. Thus, phosphate seems to play a crucial role in the pathophysiology of vascular calcification $[1,29]$.

\section{Mechanisms of vascular calcification in hyperphosphatemia}

The mechanisms promoting the initiation and progression of vascular calcification show similarities to those accomplishing physiological bone formation [35, 36] involving osteo-/chondrogenic transdifferentiation as well as apoptosis of vascular cells, decreased availability of calcification inhibitors, extracellular vesicle release, and remodeling of extracellular matrix $[2,6]$. These mechanisms are not mutually exclusive. Vascular smooth muscle cells (VSMCs) play a key role during vascular calcification (Fig. 1) [3, 6, 15, 17].

Under physiological conditions, calcium and phosphate concentrations exceed their solubility [37] and endogenous local and circulating calcification inhibitors are required to prevent the ectopic precipitation of calcium and phosphate [2]. The strongest endogenous inhibitor of mineralization is considered to be inorganic pyrophosphate $[3,6]$ found in relatively high levels in blood [1], but also being locally produced by VSMCs [10]. VSMCs produce and release pyrophosphate in the extracellular space, effects involving the ectonucleotide pyrophosphatase/phosphodiesterase (ENPP1) and the transmembrane protein ankylosis protein homolog (ANKH) $[10,38]$. In addition, Fetuin$\mathrm{A}$ is a circulating protein that can bind directly calcium or hydroxyapatite to inhibit the growth of hydroxyapatite crystals $[1,2]$. Dietary protein restriction in rats with CKD is associated with reduced systemic Fetuin-A concentrations and increased vascular calcification [39]. VSMCs can take up Fetuin-A from the extracellular space and produce several other inhibitory proteins such as matrix-Gla protein, osteopontin, or osteoprotegerin [1,2], which are further loaded into extracellular vesicles to prevent vascular mineralization [3]. Various pathological factors, especially high extracellular phosphate levels, are able to suppress the production of calcification inhibitors and to promote the release of exosomal vesicles lacking these inhibitors, but with increased load of pro-calcific proteins such as tissue-nonspecific alkaline phosphatase (ALPL) [40, 41]. These could form microcalcifications and serve as a nidus for calcium phosphate precipitation and growth of calcium phosphate crystals [7, 40, 42].

Hyperphosphatemia may further lead to extracellular matrix remodeling in the medial layer of the vasculature $[2,43]$. Increased production of matrix metalloproteinases (MMPs) by VSMCs [44-47] such as MMP2 or MMP9 [43, $46,47]$ and further degradation of various extracellular matrix proteins including elastic fibers provide additional nidus sites for calcium phosphate precipitation $[2,7,43]$. Along those lines, excessive levels of the cysteine protease cathepsin $\mathrm{S}$ leads to cleavage of elastin and generation 
Fig. 1 Role of vascular smooth muscle cells in vascular calcification. Following exposure to pro-calcific factors, most importantly hyperphosphatemia, vascular smooth muscle cells (VSMCs) are able to transdifferentiate into an osteo-/ chondrogenic phenotype. This process is characterized and, at least partly, mediated by expression of osteogenic transcription factors such as CBFA1, MSX2, SOX9, and osterix. The osteo-/ chondroblast-like cells actively promote calcification by reduced availability of calcification inhibitors, apoptosis, and apoptotic body release as well as release of calcifying extracellular vesicles, remodeling of the extracellular matrix and elastin degradation, and a pro-inflammatory state with release of pro-inflammatory cytokines and oxidative stress. These create a pro-calcifying environment, which allows for active mineralization of the vasculature

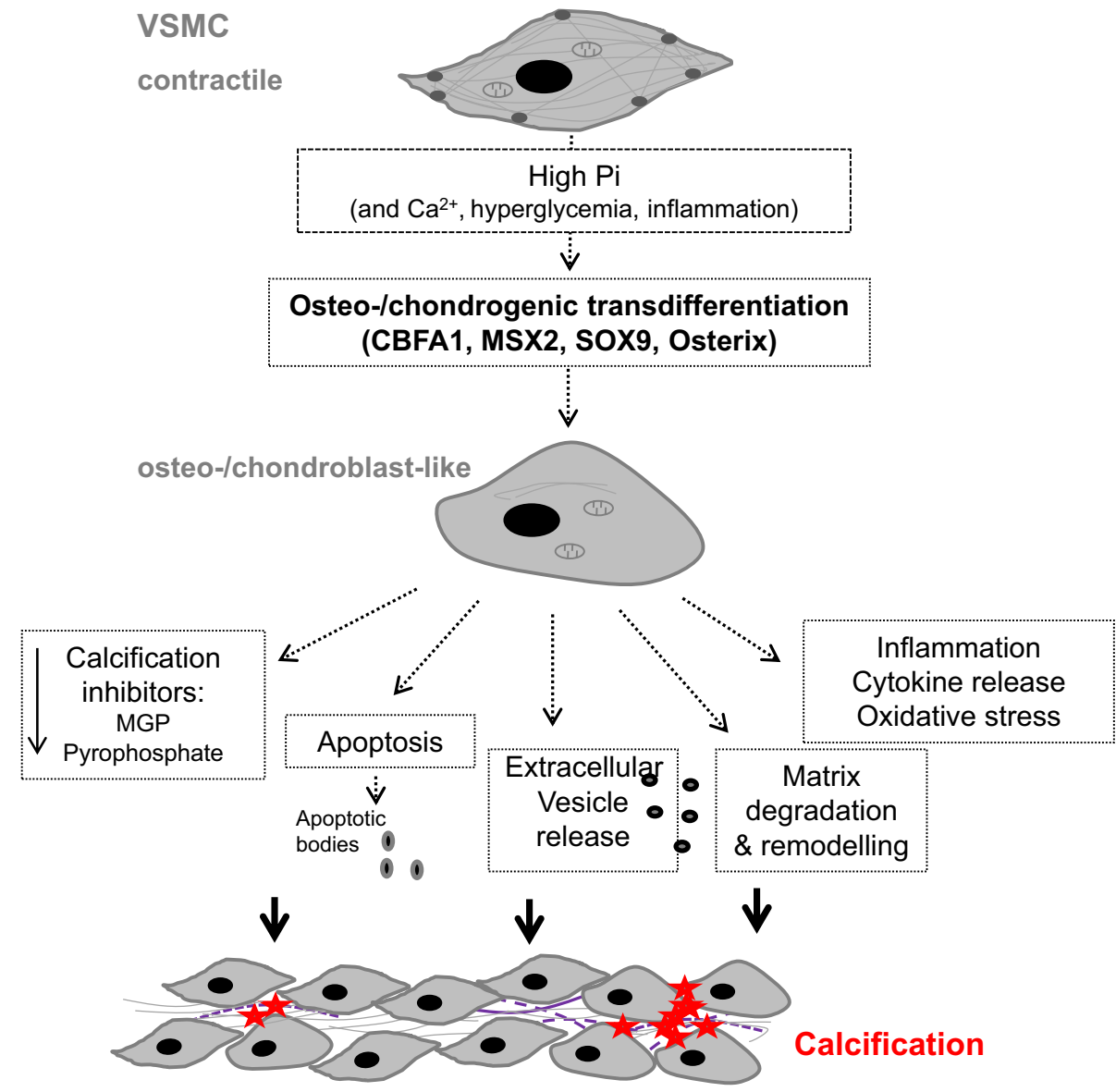

bioactive elastin peptides [48], which may act directly on VSMCs to further accelerate vascular calcification [2, 48, 49] during hyperphosphatemia. Furthermore, in the presence of phosphate, VSMCs synthesize increased levels of collagen, leading to deposition of a collagen-enriched extracellular matrix [7, 10, 50, 51]. More importantly, phosphate induces the expression of enzymes such as procollagen-lysine, 2-oxoglutarate 5-dioxygenase 1 (PLOD1), or lysyl oxidase (LOX) in VSMCs [52] that mediate collagen cross-linking and supramolecular organization [53], which seems to represent a critical event during extracellular matrix remodeling associated with vascular tissue mineralization $[50,52]$.

Apoptosis is another key mechanism promoting vascular tissue mineralization [54, 55]. Previous studies showed that high extracellular phosphate levels induce apoptosis and necrosis of VSMCs [1, 2, 16, 46]. Under such circumstances, VSMCs release apoptotic bodies, which could serve as a nidus for calcium phosphate deposition $[1,42,54,56]$. In addition, apoptosis of VSMCs may lead to medial VSMC loss and degeneration as well as elastin breaks, cyst-like structures, and changes in extracellular matrix composition within the medial layer of the arteries [55, 57], effects that may also contribute to vascular mineralization $[2,7$,
43]. Inhibition of apoptosis with caspase inhibitor is able to reduce VSMC mineralization [54].

In vascular tissue, calcification is actively promoted by osteoblast- and chondroblast-like cells $[36,58]$. In the media, VSMCs are able to change their phenotype from a contractile into an osteo-/chondrogenic phenotype under high phosphate conditions [6, 17]. Osteo-/chondrogenic transdifferentiation of VSMCs precedes and is required for vascular tissue mineralization [17, 58, 59]. Further sources of osteo-/chondroblast-like cells in the vasculature include pericytes [60], myofibroblasts in the adventitia [7, 61], or vascular progenitor cells [62].

\section{Phosphate-induced osteo-/chondrogenic transdifferentiation of VSMCs}

In response to high extracellular phosphate levels, VSMCs are able to change their phenotype into osteo-/chondroblastlike cells actively promoting vascular mineralization [46, $63,64]$. These transdifferentiated VSMCs lose their contractile phenotype in favor of a more mesenchymal one and gain similar properties as osteoblasts and chondroblasts [7]. They express osteogenic transcription factors such as msh homeobox 2 (MSX2), core-binding factor $\alpha-1$ (CBFA1) [46, 
63-65] or osterix [66], as well as chondrogenic transcription factors including SRY-Box 9 (SOX9) [46, 67-69]. The transcription factor CBFA1 (also known as RUNX2) plays a decisive role in vascular calcification [3]. Deficiency of CBFA1 in VSMCs prevents vascular osteo-/chondrogenic transdifferentiation and calcification [70, 71]. The transcription factor MSX2 induces the expression of CBFA1 and osterix in VSMCs [72]. Osterix is up-regulated by CBFA1 [73] and required for its full activation [10]. In addition, SOX9 may cooperate with CBFA1 to suppress the smooth muscle phenotype and promote transdifferentiation of VSMCs [69].

In these VSMCs, the expression of smooth muscle-specific proteins such as $\alpha$-smooth muscle actin ( $\alpha$ SMA) or smooth muscle protein $22-\alpha$ (SM22- $\alpha$ ) is reduced [58]. The phosphate-induced increase of osteogenic transcription factor expression is considered an event prior to downregulation of VSMC-specific markers [74, 75].

The osteo-/chondrogenic transcription factors further induce the expression of osteogenic- and chondrogenic-specific proteins in VSMCs such as osteocalcin, type I collagen, bone morphogenetic protein-2 (BMP-2), or ALPL [2, 6, 63, $76,77]$. ALPL is a key regulator of vascular calcification $[7,76]$. Increased ALPL activity is a decisive event in vascular calcification [7]. Similar as in bone, ALPL degrades inorganic pyrophosphate to allow unrestrained tissue mineralization $[7,10]$.

The osteo-/chondrogenic transdifferentiated VSMCs may promote the calcification of vascular tissue by producing a local pro-calcifying environment and nidus sites for precipitation of calcium and phosphate as well as growth of calcium phosphate crystals.

\section{Signaling pathways regulating VSMCs calcification during high phosphate conditions}

Extracellular phosphate is a signaling molecule [78] that induces various changes in VSMCs via the regulation of intracellular pathways $[46,51,63,64]$. The signaling pathways controlling osteo-/chondrogenic transdifferentiation of VSMCs and, thus, vascular calcification under elevated phosphate conditions are extremely complex and still incompletely understood. Identification of the critical intracellular pathways regulating phosphate-induced vascular calcification may provide the basis for therapeutic strategies to reduce the progression of vascular calcification in CKD. A significant progress has been made in this field and some recent observations are highlighted in this review.

\section{Transduction of phosphate signals to VSMCs}

How VSMCs sense elevated extracellular phosphate levels is still ill defined. Toll-like receptors may be involved in phosphate-sensing [79]. In addition, calcium phosphate nanoparticles can be internalized and dissolved in lysosomes, thus, triggering intracellular signaling effects [6]. Phosphate can be transported into VSMCs via the type III sodiumdependent phosphate transporters PIT1 and PIT2 [2, 15].

PIT1 is well described to mediate the effects of phosphate in VSMCs via phosphate transport-dependent and phosphate transport-independent functions [80, 81]. Interestingly, PIT1 is most abundant in cells at the endoplasmic reticulum [82] and the exact mechanisms how PIT1 mediates its effects on vascular calcification are not finally defined. PIT1-downstream signaling involves the activation of ERK1/2 MAP-kinase [75, 81] and leads to up-regulation of CBFA1 and ALPL expression in VSMCs [15, 80, 81]. The downstream effects of ERK1/2 during vascular calcification are still incompletely understood. Silencing of PIT1 is sufficient to suppress phosphate-induced osteoinduction and mineralization of VSMCs [80]. PIT1 functions are apparently modulated mainly by changes in expression levels [66, 83]. Accordingly, phosphate up-regulates PIT1 expression in VSMCs [64, 84]. PIT1 expression can be transcriptionally regulated in VSMCs by several pathways including SAPK/ JNK MAP-kinase signaling [85], $\beta$-catenin signaling [84], or transcription factor-4 (ATF4) [86]. Activation of the mineralocorticoid receptor (MR) in VSMCs may directly up-regulate PIT1 transcription [59, 66]. PIT1 is involved in the pro-calcific effects of aldosterone in VSMCs [66]. Elevated phosphate levels induce the expression of aldosterone synthase in VSMCs via disruption of apurinic/apyrimidinic endodeoxyribonuclease 1 (APEX1)-dependent gene suppression, while MR blockade is able to reduce PIT1-dependent osteoinductive signaling and calcification of VSMCs during hyperphosphatemia [64].

PIT2 is up-regulated together with PIT1 in the vasculature in uremic conditions [87]. These two transporters were considered to play a redundant role in phosphate-induced osteoinduction in VSMCs [88]. However, the recent findings suggest that PIT2 may even protect against vascular calcification by the up-regulation of osteoprotegerin [89], a key regulator of bone metabolism and inhibitor of vascular calcification $[31,90]$.

\section{Phosphate-dependent osteoinductive signaling cascades}

Presumably, a multitude of intracellular signaling pathways and para/autocrine signals orchestrate the calcification response to phosphate. Elevated extracellular phosphate levels trigger activation of the transcription factor nuclear factor 
" "kappa-light-chain-enhancer" of activated B cells (NF-kB) in VSMCs $[63,79,91,92]$. Activation of the NF-kB pathway is critically important for phosphate-induced vascular calcification [63, 79, 91-93]. NF-kB signaling promotes VSMC mineralization in part by inducing MSX2 expression and upregulating CBFA1 to increase ALPL expression [63, 72, 93]. Moreover, NF-kB increases the expression of tristetraprolin (TTP), an RNA-destabilizing protein that reduces ANKH mRNA levels and, thus, may modify the production or release of pyrophosphate in the extracellular space [91, 93]. In addition, smooth muscle-specific deficiency of NF-KB or NF-kB inhibition is sufficient to block vascular calcification during hyperphosphatemia $[63,79,91,92]$.

The deleterious effects of phosphate in the cardiovascular system may also involve the serum- and glucocorticoidinducible kinase (SGK1) [94]. SGK1, a serine/threonine protein kinase, is activated via phosphatidylinositide3-kinase (PI3K), 3-phosphoinositide-dependent kinase 1 (PDK1), and mammalian target of rapamycin (mTOR) signaling [95], and orchestrates the cellular response to various pathological triggers [94-98]. In VSMCs, SGK1 expression and activity are increased by phosphate and its activation plays a key role in phosphate-induced vascular calcification [93]. Inhibition or deficiency of SGK1 is able to suppress vascular calcification during hyperphosphatemia [93]. SGK1 promotes osteo-/chondrogenic transdifferentiation and calcification of VSMCs through the activation of the transcription factor NF-kB [93]. SGK1 directly phosphorylates IKK $\alpha$ to induce NF-kB activation, an effect requiring also IKK $\beta$ [99]. Furthermore, phosphorylation-dependent ubiquitination and degradation of $\mathrm{IkB} \alpha$ leads to NF-kB nuclear translocation, NF-kB-dependent target gene transcription [63, 94], and subsequent osteo-/chondrogenic transdifferentiation of VSMCs. Thus, interference with SGK1/NF-kB signaling pathway may preserve an anti-calcific environment of VSMCs and ameliorate vascular calcification during hyperphosphatemia.

AKT (also known as protein kinase B) signaling contributes to the complex machinery underlying VSMC osteoinduction $[56,100,101]$. Phosphate reduces AKT phosphorylation in VSMCs [56, 100], while both pro-calcific effects [101] and protective effects against vascular calcification [101, 102] of AKT activation have been described. AKT and SGK1 are able to phosphorylate and inactivate glycogen synthase kinase 3 (GSK-3) [103, 104]. Vascular AKT/SGKresistance of GSK-3 is able to ameliorate vascular osteoinduction and calcification [104]. The PI3K-dependent pathways, thus, have an essential, but diverse and complex role during vascular calcification, which requires further study to dissect pro- and anti-calcific effects.

The WNT/ $\beta$-catenin pathway is established as a major component of the osteoinductive signaling cascade and a mediator of vascular calcification [84, 105-110]. WNT are ligand proteins that bind at the cell surface receptors of the Frizzled family and lipoprotein receptor-related protein (LRP)-5/6 for intracellular signaling [109], leading to $\beta$-catenin activation, nuclear translocation, and target gene expression $[84,109]$. GSK $3 \beta$ activity promotes $\beta$-catenin phosphorylation and its degradation by the proteasome, interfering with WNT-signaling [103, 104]. WNT/ $\beta$-catenin pathway is activated by phosphate $[108,110]$, and participates in phosphate-induced osteo-/chondrogenic transdifferentiation and calcification of VSMCs [84, 105, 106]. Activation of the WNT/ $\beta$-catenin pathway is required for the downstream effects of MSX2 [105] and contributes to osteo-/chondrogenic transdifferentiation of VSMCs, at least in part, by directly up-regulating CBFA1 [106] as well as PIT1 gene expression [84] during hyperphosphatemia. In addition, WNT/ $\beta$-catenin may further participate to vascular calcification by induction of MMP2 and MMP9 in VSMCs [47]. Furthermore, interference with WNT/ $\beta$-catenin signaling activation is able to suppress osteo-/chondrogenic transdifferentiation of VSMCs and vascular calcification [107, $108,110-112]$. WNT/ $\beta$-catenin pathway inhibitors such as Dickkopf-related protein 1 (DKK1) [108] or secreted frizzled-related proteins (SFRPs) [112] showed anti-calcific effects in VSMCs during in vitro hyperphosphatemia. However, the systemic effects of WNT/ $\beta$-catenin may be more complex, as DKK1 inhibition also promoted bone formation and prevented vascular calcification in a CKD mouse model [113].

\section{Counterregulatory pathways during phosphate-induced VSMCs calcification}

Phosphate-induced activation of NF-kB signaling in VSMCs can be counteracted by the endogenous inhibitor TNFAIP3, also known as A20 [63]. TNFAIP3 is a zinc-finger protein, which interferes with NF-kB activation via $\operatorname{IkB} \alpha$ [114]. In accordance, up-regulation of TNFAIP 3 expression is able to inhibit osteo-/chondrogenic transdifferentiation and calcification of VSMCs following phosphate exposure [63]. In VSMCs, TNFAIP3 expression can be increased at the transcriptional level by the elevated extracellular $\mathrm{Zn}^{2+}$ levels via the $\mathrm{Zn}^{2+}$-sensing receptor ( $\left.\mathrm{ZnR}\right)$, also known as $\mathrm{G}$ proteincoupled receptor 39 (GPR39) [63]. Both in vitro and in vivo $\mathrm{Zn}^{2+}$ supplementation up-regulates vascular TNFAIP3 expression and suppresses NF-kB-dependent osteo-/chondrogenic signaling as well as calcification of VSMCs during hyperphosphatemia [63].

Similarly, activation of another membrane receptor, the $\mathrm{Ca}^{2+}$-sensing receptor (CASR), may interfere with phosphate-induced VSMC calcification [51, 115, 116]. CASR can be activated by extracellular $\mathrm{Ca}^{2+}$, but also by the other cations such as $\mathrm{Mg}^{2+}, \mathrm{Gd}^{3+}$, amino acids, or polyamines [51, 117]. The downstream signaling involved in the anti-calcific 
effects of CASR activation is, however, still incompletely understood $[51,116]$. Nonetheless, calcimimetics increase CASR expression and reduce mineralization of VSMCs [118]. Moreover, activation of the vitamin $\mathrm{D}_{3}$ receptor (VDR) inhibits VSMCs mineralization by up-regulating CASR expression [115]. Along those lines, $\mathrm{Mg}^{2+}$ supplementation showed inhibitory effects on vascular calcification in vitro and in animal models [119-121]. In addition to activation of the CASR [51], $\mathrm{Mg}^{2+}$ may also inhibit WNT/ $\beta$ catenin signaling [110] or directly interfere with calcium phosphate precipitation [122] to suppress vascular tissue mineralization. The so far known mechanisms involved in the anti-calcific properties of $\mathrm{Mg}^{2+}$ are discussed in detail elsewhere [119-121]. Taken together, activation of ZnRdependent as well as CASR-dependent anti-calcific intracellular pathways interferes with phosphate-induced signaling, osteo-/chondrogenic transdifferentiation of VSMCs, and, thus, vascular calcification.

Another factor that may interfere with osteo-/chondrogenic pathways in VSMCs is the FGF23 co-receptor $\alpha$-klotho, which may also circulate as soluble humoral factor [123-125]. In VSMCs, according to some studies, klotho expression is down-regulated by phosphate [124], an effect associated with activated mTOR signaling [123], which augments vascular calcification [123, 124]. However, other studies found no evidence of klotho expression in VSMCs [126]. Soluble klotho has been suggested to contribute to vascular calcification [125] and may be able to inhibit the phosphate uptake via PIT1 in VSMCs [125]. The suggested protective effects of klotho on vascular calcification involve the inhibition of the WNT/ $\beta$-catenin signaling pathway $[127,128]$. In addition, both anti- [129] and pro-calcific [130] effects of FGF23 were described. Further research is required to elucidate the various functions and possible modifiers of the effects of vascular FGF23/klotho.

\section{Cytokine signaling and inflammatory responses}

Pro-inflammatory intracellular signaling in VSMCs also seems to induce or augment osteo-/chondrogenic transdifferentiation of VSMCs triggered by elevated phosphate levels $[13,67,68,131-133]$. Phosphate is associated with vascular inflammation [67, 68, 132, 134-136]. Accordingly, a recent study showed that phosphate overload directly induces local inflammation in cultured VSMCs and systemic and vascular inflammation in vivo [135]. VSMCs produce proinflammatory cytokines such as TNF $\alpha$, IL-1 $\beta$, IL-6, BMP-2, or TGF $\beta 1$ [66-68, 72, 137, 138], powerful stimulators of VSMC osteoinduction by modulating intracellular signaling $[72,138]$.

Exposure to calcium phosphate crystals induces IL- $1 \beta$ release via the activation of spleen tyrosine kinase (SYK), apparently independent from inflammasome activation [25].
Nonetheless, inflammasome activation is required for vascular calcification during hyperphosphatemia [137], effects presumably involving TNF $\alpha$ [139]. TNF $\alpha$ further increases MSX2 expression in VSMCs via the NF-kB pathway to induce osteo-/chondrogenic transdifferentiation of VSMCs [72]. In addition, the RANKL/RANK system augments vascular calcification via NF-kB, which can be blocked by the inhibitory RANKL-decoy receptor osteoprotegerin [140]. Similarly, the SGK1/NF-kB osteoinductive pathway may be activated by IL-18 [133], resulting in aggravation of phosphate-induced VSMCs mineralization [133, 141]. Furthermore, together with the NF-kB pathway, WNT/ $\beta$ catenin signaling may modulate pro-inflammatory signaling cascades in VSMCs in response to hyperphosphatemia [127, 142, 143].

In addition, TNF $\alpha$-mediated VSMC calcification is also associated with increase of BMP-2 signaling [144]. Phosphate induces BMP-2 expression in VSMCs $[26,79]$ and BMP-2 mediates the effects of phosphate in vascular calcification [134, 145]. BMP-2 triggers VSMC osteoinduction [146], at least partly, via MSX2 up-regulation [147] and involves the WNT/ $\beta$-catenin pathway [145] as well as generation of cellular oxidative stress [148]. Furthermore, the pro-calcific effects of BMP-2 in VSMCs involve the upregulation of PIT-1 expression [134] and SMAD signaling [148].

IL-6 is another key mediator of phosphate-induced vascular calcification [135, 149-151]. In VSMCs, IL-6 regulates various pathways leading to osteo-/chondrogenic transdifferentiation of VSMCs including activation of BMP-2-WNT/ $\beta$ catenin signaling [152], RANKL [149], and STAT3 pathway $[153,154]$ or induction of oxidative stress [138, 151].

Moreover, TGF $\beta 1$ was described as a strong promoter of osteoinduction and calcification of VSMCs [67, 68, 155]. TGF $\beta 1$ expression is increased by phosphate in VSMCs [67, 68]. TGF $\beta 1$-downstream osteoinductive signaling includes the transcription factor NFAT5 (also known as TonEBP), which mediates the SOX9-dependent up-regulation of CBFA1 in VSMCs $[67,68,155,156]$. TGF $\beta 1$ may also contribute to vascular calcification by inducing cellular senescence, including up-regulation of plasminogen activator inhibitor PAI-1, which exerts pro-calcific effects [67, 155, 157]. Most importantly, inhibition of TGF $\beta 1$-dependent signaling is able to suppress phosphate-induced vascular calcification $[67,68,155]$.

\section{Signaling pathways induced by calcium phosphate nanoparticles and CPPs}

Phosphate affects VSMCs calcification through intracellular effects of calcium phosphate nanoparticles [26], which can be engulfed by lysosomes [6,63]. Calcium phosphate nanoparticles are endocytosed by VSMCs, which further leads 
to release of $\mathrm{Ca}^{2+}$ from the lysosomes, elevated intracellular $\mathrm{Ca}^{2+}$ levels, and subsequent apoptosis of VSMCs $[6,136]$ or $\mathrm{Ca}^{2+}$-induced inflammasome activation [158]. The osteogenic lysosomal effects are dependent on the acidic lysosomal pH $[6,136]$. Accordingly, alkalinisation of lysosomal $\mathrm{pH}$ with $\mathrm{NH}_{4} \mathrm{Cl}$ [67], bafilomycin A1, or methylamine [68] is able to suppress phosphate-induced VSMCs osteo-/chondrogenic transdifferentiation and calcification. Lysosomes may also regulate several other osteoinductive signaling pathways, besides inducing apoptosis of VSMCs. The transfer of lysosomes loaded with LDL/cholesterol from macrophages into VSMCs may trigger the phenotypical transdifferentiation of VSMCs [159]. Moreover, lysosomes are involved in maturation of various proteins, including pro-TGF $\beta$ [160], which may affect VSMCs osteo-/chondrogenic transdifferentiation $[67,68,119]$. Thus, the lysosomes are key organelles for the intracellular osteoinductive effects of phosphate $[6$, $67,68,136]$.

Calcium phosphate crystal formation is inhibited by Fetuin-A and the formation of calciprotein particles (CPPs) [31]. However, these may undergo transition from the amorphous (primary CPPs) to the crystalline (secondary CPPs) phase $[12,30,161]$, which is promoted by various physicochemical factors [30]. The secondary CPPs may also trigger vascular calcification via a cell-mediated process $[28,161$, $162]$ by inducing osteo-/chondrogenic transdifferentiation of VSMCs [28]. Secondary CPPs, but not primary CPPs, are able to trigger directly VSMC calcification $[161,162]$. These effects involve the uptake of CPPs by VSMCs and an increase of intracellular $\mathrm{Ca}^{2+}$ levels [161] followed by the induction of cellular oxidative stress and pro-inflammatory responses $[161,162]$ to promote mineralization. Thus, due to its antioxidant properties, hydrogen sulfide suppresses VSMC calcification promoted by CPPs [162]. Increased expression and release of the pro-inflammatory cytokine $\mathrm{TNF} \alpha$ and activation of TNF $\alpha / \mathrm{TNFR} 1$ system is critically important for CPPs-induced VSMC calcification [161].

The properties of CPPs formation may also be utilized for novel diagnostic approaches [12]. A nanoparticle-based assay was developed, which detects the influence of serum on spontaneous transformation of primary CPPs into secondary CPPs and, thus, the balance between inhibitors and promoters of calcification in the serum [12]. Serum calcification propensity was suggested as a biomarker for cardiovascular disease [163] and shown to predict cardiovascular and all-cause mortality in CKD [164, 165].

\section{Oxidative stress-downstream signaling pathways}

Oxidative stress contributes to vascular calcification in CKD [166]. Phosphate induces oxidative stress in VSMCs by triggering an imbalance between the antioxidant and the reactive oxygen species (ROS)-generating systems [10, 46, 138,
167]. Similarly, the superoxide-generating NAPDH oxidase system is associated with vascular calcification [168]. Oxidative stress mediates, at least partly, the effects of phosphate on osteo-/chondrogenic transdifferentiation and calcification of VSMCs [46, 138, 169]. In contrast to the acidification of lysosomes, intracellular alkalinisation by phosphate uptake via PIT1 [170] may contribute to phosphate-induced ROS production and oxidative stress $[46,170]$.

The downstream effectors of oxidative stress leading to osteo-/chondrogenic transdifferentiation of VSMCs include a multitude of signaling pathways. Oxidative stress is a strong promoter of CBFA1 expression and osteo-/chondrogenic transdifferentiation of VSMCs [169, 171, 172]. Furthermore, oxidative stress promotes osteoinduction in VSMCs via the ERK1/2 MAP-kinase [171, 172] as well as p38 MAP-kinase pathways [171]. Activation of either ERK1/2 [81, 171, 172] or $\mathrm{p} 38$ MAP-kinase signaling pathways $[171,173]$ promotes vascular calcification. P38 MAP-kinase may directly activate CBFA1 [173], contribute to inflammasome activation [174], and activate NF-kB via mitogen- and stress-activated protein kinase-1 (MSK1) [175]. ROS were also shown to activate the transcription factor NF-kB and NF-kB-dependent osteoinductive signaling pathways [167] and promote pro-inflammatory responses of VSMCs [176]. Oxidative stress leads to the increased expression of matrix metalloproteinases $[46,177]$ that degrade extracellular matrix to allow mineralization $[43,44]$ as well as increased PAI-1 expression [16, 46, 155]. In addition, oxidative stress may induce the apoptosis of VSMCs [178] to promote vascular mineralization [1].

In accordance, antioxidants blunt osteo-/chondrogenic transdifferentiation of VSMCs and vascular calcification [179]. Similarly, Fibulin-3, an extracellular matrix glycoprotein, inhibits phosphate-induced phenotypical transdifferentiation and calcification of VSMCs through inhibition of cellular oxidative stress [46]. Conversely, loss of cytosolic serine hydroxymethyl transferase 1 (SHMT1), a key enzyme in one carbon metabolism, aggravates VSMC osteoinduction and calcification during elevated phosphate conditions by inducing oxidative stress [180]. SHMT1 is, however, upregulated following phosphate treatment in VSMCs, a finding pointing to a role of SHMT1 in the cellular response that limits calcification [180].

Nitric oxide (NO) levels are associated with oxidative stress in VSMCs [16]. NO deficiency may induce oxidative stress $[16,181]$ and, thus, may promote osteo-/chondrogenic transdifferentiation of VSMCs with subsequent mineralization of vascular tissue [16]. Impaired NO production leads to the aggravation of phosphate-induced vascular calcification [16]. Conversely, NO prevents vascular calcification and inhibits osteo-/chondrogenic signaling pathways by interfering with TGF $\beta 1 / \mathrm{PAI}-1$ signaling $[16,155]$. Thus, NO is 
a key factor that regulates intracellular signaling pathways controlling vascular calcification.

\section{Apoptosis signaling pathways}

In response to phosphate, a multitude of up-stream signaling cascades may lead eventually also to the activation of proapoptotic signaling pathways in VSMCs $[6,56,74,178,182$, 183]. A key event is represented by the downregulation of growth arrest-specific gene 6 (Gas6) and its receptor tyrosine kinase Axl [74, 182, 183]. Phosphate reduces the expression of Gas6 and Axl in VSMCs [184], leading to Bcl2 inactivation, activation of the pro-apoptotic protein Bcl2-associated death promoter (Bad), and subsequent caspase-3 activation and VSMC apoptosis [74, 182]. Gas6/Axl activates Bcl2 via AKT [183], a key downstream signaling pathway of the Gas6-mediated VSMC survival [183]. In accordance, phosphate inhibits AKT phosphorylation in VSMCs [56, $100,183]$, while activation of the PI3K/AKT pathway may prevent phosphate-induced apoptosis of VSMCs [56]. Similarly, vitamin K2 [182], iron citrate [185], estrogens [186], testosterone [187], $\alpha$-lipoic acid [188], or statins [183, 184] inhibit phosphate-induced VSMCs apoptosis by restoring the Gas6-dependent anti-apoptotic pathway, effects leading to a reduction in VSMC calcification [54, 55]. A key upstream regulator of Gas6 expression in VSMCs is the AMPactivated protein kinase (AMPK) [189, 190]. AMPK activity is suppressed in the presence of phosphate [191] and AMPK activation reduces VSMC calcification [189-191], effects involving inhibition of oxidative stress-mediated apoptosis [189].

\section{Other factors involved in the regulation of osteoinductive pathways}

Several additional cellular factors such as components of the epigenetic regulation [192] including microRNAs [193], DNA methylation [194-196], or histone modifications [197] contribute to the osteoinductive intracellular signaling pathways during hyperphosphatemia. The role of epigenetics [192] as well as the so far known microRNAs [193, 198, 199] involved in vascular calcification have been reviewed in detail elsewhere. The microRNAs were shown to have a decisive role in osteo-/chondrogenic transdifferentiation of VSMCs by regulating various cellular processes during hyperphosphatemia such as gene expression [192, 193, 198-202], inflammasome activation [137], apoptosis [201, 203], senescence [154, 201], or endoplasmic reticulum stress [203]. Moreover, the recent findings describe that microRNAs are involved in the regulation of several intracellular pathways controlling osteo-/chondrogenic phenotypic switch of VSMCs including the WNT/ $\beta$-catenin pathway [107],
PI3K signaling [204], STAT3 pathway [154], or TGF $\beta 1 /$ SMAD signaling [205].

In addition, aging-related epigenetic changes were shown to influence vascular calcification [198, 201, 206-209]. Hyperphosphatemia promotes premature senescence and aging of VSMCs [206, 210], at least in part, by suppressing Sirtuin 1 expression $[201,211]$ and subsequent p21 activation [211]. During senescence, VSMCs are characterized by telomere shortening, increased oxidative DNA damage or impaired DNA repair [212], factors driving osteo-/chondrogenic transdifferentiation of VSMCs [207-209]. Furthermore, senescent VSMCs are associated with increased expression of BMP-2 as well as pro-inflammatory cytokines such as IL-1 $\beta$, IL-6, or TNF $\alpha$ [209], well-known promoters of VSMC calcification [72, 146, 147, 151]. In accordance, preventing cellular senescence by increasing Sirtuin 1 levels in VSMCs is able to interfere with phosphate-induced VSMC osteo-/chondrogenic transdifferentiation and calcification $[211,213]$.

Other cellular factors, which contribute to the osteoinductive intracellular pathways during hyperphosphatemia, include autophagy [214, 215], endoplasmic reticulum stress [172, 203], or mitochondrial dysfunction [188, 189, 213]. Increase of cellular autophagy [185, 214, 216], restoration of mitochondrial function [188, 189, 213], or inhibition of endoplasmic reticulum stress [172] were all described to interfere with phosphate-induced vascular calcification.

\section{Interplay between signaling pathways in the regulation of vascular calcification}

Phosphate triggers osteo-/chondrogenic transdifferentiation and calcification of VSMCs by regulating a multitude of signaling pathways. As described above, these processes are controlled by an extremely complex cellular network of signaling pathways characterized by many cross talks and close interactions between these signaling cascades (Fig. 2). Alteration of central factors of this network affects also on the interconnected signaling pathways and, thus, may be effective in interfering with the pro-calcific effects of phosphate in VSMCs.

Clearly, elucidating the complex interplay of the cellular responses to high phosphate exposure requires further study, to connect the currently identified pathways, to define the relative importance during different stages of the process, and, finally, to gain a more comprehensive understanding of the onset and progression of vascular calcification in CKD. 


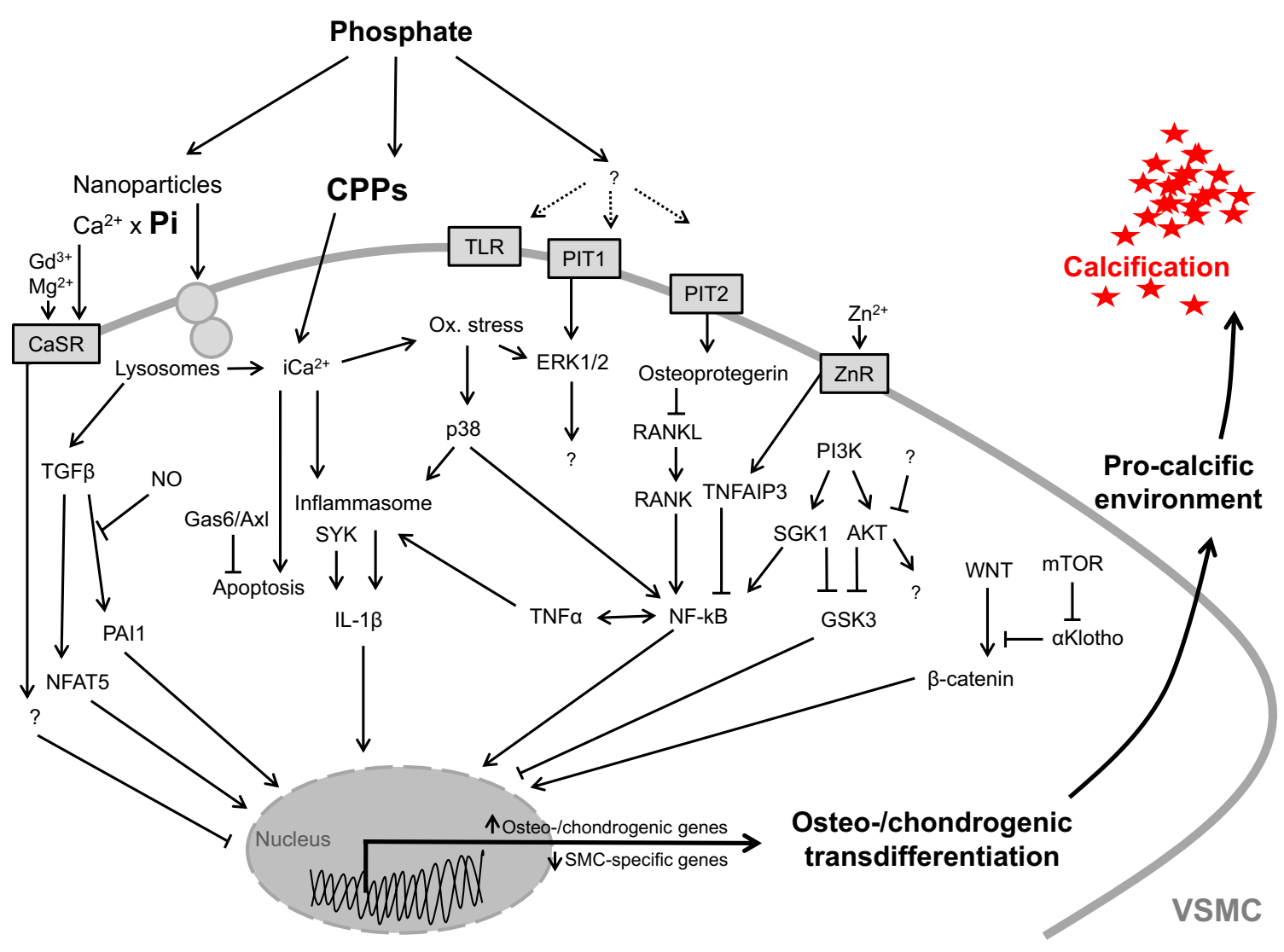

Fig. 2 Critical signaling pathways involved in osteo-/chondrogenic transdifferentiation of vascular smooth muscle cells. Simplified schematic illustration of important phosphate-induced signaling pathways discussed in this review, ultimately leading to osteo-chondrogenic

\section{Conclusions}

Elevated phosphate concentrations trigger vascular calcification through a complex and highly regulated process. A key role during vascular calcification is attributed to VSMCs, which actively promote mineralization by mechanisms involving osteo-/chondrogenic phenotypical transdifferentiation. A complex interplay between different intracellular signaling cascades tightly controls phosphate-induced osteo-/chondrogenic transdifferentiation of VSMCs. Identification of the critical intracellular pathways regulating vascular calcification may help to develop feasible therapeutic approaches to reduce the progression of vascular calcification in CKD.

Acknowledgements Open access funding provided by Johannes Kepler University Linz. The work in the author's lab was supported by the Berlin Institute of Health (BIH), the Else Kröner-Fresenius-Stiftung, the Deutsche Forschungsgemeinschaft (AL2054/1-1, VO2259/2-1) and the DZHK (German Centre for Cardiovascular Research). transdifferentiation of vascular smooth muscle cells (VSMCs), development of a pro-calcifying environment, and vascular calcification. For details and abbreviations, see the full text

\section{Compliance with ethical standards}

Conflict of interest AP is an employee and stockholder of Calciscon AG which commercializes the Calcification propensity test. Otherwise, the authors declare that they have no conflict of interest.

Open Access This article is distributed under the terms of the Creative Commons Attribution 4.0 International License (http://creativeco mmons.org/licenses/by/4.0/), which permits unrestricted use, distribution, and reproduction in any medium, provided you give appropriate credit to the original author(s) and the source, provide a link to the Creative Commons license, and indicate if changes were made.

\section{References}

1. Paloian NJ, Giachelli CM (2014) A current understanding of vascular calcification in CKD. Am J Physiol Renal Physiol 307(8):F891-F900

2. Shanahan CM et al (2011) Arterial calcification in chronic kidney disease: key roles for calcium and phosphate. Circ Res 109(6):697-711

3. Schlieper G et al (2016) Vascular calcification in chronic kidney disease: an update. Nephrol Dial Transplant 31(1):31-39 
4. Vattikuti R, Towler DA (2004) Osteogenic regulation of vascular calcification: an early perspective. Am J Physiol Endocrinol Metab 286(5):E686-E696

5. Elliott RJ, McGrath LT (1994) Calcification of the human thoracic aorta during aging. Calcif Tissue Int 54(4):268-273

6. Lanzer $P$ et al (2014) Medial vascular calcification revisited: review and perspectives. Eur Heart J 35(23):1515-1525

7. Demer LL, Tintut Y (2008) Vascular calcification: pathobiology of a multifaceted disease. Circulation 117(22):2938-2948

8. Nitschke Y, Rutsch F (2017) Inherited arterial calcification syndromes: etiologies and treatment concepts. Curr Osteoporos Rep 15(4):255-270

9. Rutsch F, Nitschke Y, Terkeltaub R (2011) Genetics in arterial calcification: pieces of a puzzle and cogs in a wheel. Circ Res 109(5):578-592

10. Johnson RC, Leopold JA, Loscalzo J (2006) Vascular calcification: pathobiological mechanisms and clinical implications. Circ Res 99(10): 1044-1059

11. London GM et al (2003) Arterial media calcification in end-stage renal disease: impact on all-cause and cardiovascular mortality. Nephrol Dial Transplant 18(9):1731-1740

12. Pasch A et al (2012) Nanoparticle-based test measures overall propensity for calcification in serum. J Am Soc Nephrol 23(10): 1744-1752

13. Henaut L et al (2018) Updates on the mechanisms and the care of cardiovascular calcification in chronic kidney disease. Semin Nephrol 38(3):233-250

14. Ruderman I et al (2018) Current and potential therapeutic strategies for the management of vascular calcification in patients with chronic kidney disease including those on dialysis. Semin Dial 31(5):487-499. https://doi.org/10.1111/sdi.12710

15. Lang F et al (2013) Vascular calcification-is aldosterone a culprit? Nephrol Dial Transplant 28(5):1080-1084

16. Alesutan I et al (2016) Augmentation of phosphate-induced osteo-/chondrogenic transformation of vascular smooth muscle cells by homoarginine. Cardiovasc Res 110(3):408-418

17. Giachelli CM (2003) Vascular calcification: in vitro evidence for the role of inorganic phosphate. J Am Soc Nephrol 14(9 Suppl 4):S300-S304

18. Abramowitz M et al (2010) Serum alkaline phosphatase and phosphate and risk of mortality and hospitalization. Clin J Am Soc Nephrol 5(6):1064-1071

19. Ruospo M et al (2018) Phosphate binders for preventing and treating chronic kidney disease-mineral and bone disorder (CKDMBD). Cochrane Database Syst Rev 8:CD006023

20. Vervloet MG et al (2017) The role of phosphate in kidney disease. Nat Rev Nephrol 13(1):27-38

21. Bhan I (2014) Phosphate management in chronic kidney disease. Curr Opin Nephrol Hypertens 23(2):174-179

22. Kuro OM (2011) Phosphate and Klotho. Kidney Int 79121:S20-S23

23. Lederer E, Wagner CA (2019) Clinical aspects of the phosphate transporters NaPi-IIa and NaPi-IIb: mutations and disease associations. Pflugers Arch 471(1):137-148

24. Hruska KA et al (2008) Hyperphosphatemia of chronic kidney disease. Kidney Int 74(2):148-157

25. Dautova $Y$ et al (2018) Calcium phosphate particles stimulate interleukin-1beta release from human vascular smooth muscle cells: a role for spleen tyrosine kinase and exosome release. J Mol Cell Cardiol 115:82-93

26. Sage AP et al (2011) Hyperphosphatemia-induced nanocrystals upregulate the expression of bone morphogenetic protein-2 and osteopontin genes in mouse smooth muscle cells in vitro. Kidney Int 79(4):414-422
27. Block GA et al (2004) Mineral metabolism, mortality, and morbidity in maintenance hemodialysis. J Am Soc Nephrol 15(8):2208-2218

28. Viegas CSB et al (2018) Chronic kidney disease circulating calciprotein particles and extracellular vesicles promote vascular calcification: a role for GRP (Gla-Rich Protein). Arterioscler Thromb Vasc Biol 38(3):575-587

29. Kuroo M (2014) New developments in CKD-MBD. Why is phosphate overload harmful? Clin Calcium 24(12):1785-1792

30. Miura $\mathrm{Y}$ et al (2018) Identification and quantification of plasma calciprotein particles with distinct physical properties in patients with chronic kidney disease. Sci Rep 8(1):1256

31. Cai MM, Smith ER, Holt SG (2015) The role of fetuin-A in mineral trafficking and deposition. Bonekey Rep 4:672

32. Pasch A, Jahnen-Dechent W, Smith ER (2018) Phosphate, calcification in blood, and mineral stress: the physiologic blood mineral buffering system and its association with cardiovascular risk. Int J Nephrol 2018:9182078

33. Cancela AL et al (2012) Phosphorus is associated with coronary artery disease in patients with preserved renal function. PLoS One 7(5): e36883

34. Tonelli $\mathrm{M}$ et al (2005) Relation between serum phosphate level and cardiovascular event rate in people with coronary disease. Circulation 112(17):2627-2633

35. Alves RD et al (2014) Calcifying vascular smooth muscle cells and osteoblasts: independent cell types exhibiting extracellular matrix and biomineralization-related mimicries. BMC Genom 15:965

36. Doherty TM, Detrano RC (1994) Coronary arterial calcification as an active process: a new perspective on an old problem. Calcif Tissue Int 54(3):224-230

37. Ketteler M et al (2005) Do not be misguided by guidelines: the calcium $\times$ phosphate product can be a Trojan horse. Nephrol Dial Transplant 20(4):673-677

38. Moochhala SH (2012) Extracellular pyrophosphate in the kidney: how does it get there and what does it do? Nephron Physiol 120(4):33-38

39. Yamada $\mathrm{S}$ et al (2015) Fetuin-A decrease induced by a low-protein diet enhances vascular calcification in uremic rats with hyperphosphatemia. Am J Physiol Renal Physiol 309(8):F744-F754

40. Blaser MC, Aikawa E (2018) Roles and regulation of extracellular vesicles in cardiovascular mineral metabolism. Front Cardiovasc Med 5:187

41. Goettsch C et al (2016) Sortilin mediates vascular calcification via its recruitment into extracellular vesicles. J Clin Invest 126(4):1323-1336

42. Kapustin AN et al (2011) Calcium regulates key components of vascular smooth muscle cell-derived matrix vesicles to enhance mineralization. Circ Res 109(1):e1-e12

43. Pai A et al (2011) Elastin degradation and vascular smooth muscle cell phenotype change precede cell loss and arterial medial calcification in a uremic mouse model of chronic kidney disease. Am J Pathol 178(2):764-773

44. Chen NX et al (2011) Activation of arterial matrix metalloproteinases leads to vascular calcification in chronic kidney disease. Am J Nephrol 34(3):211-219

45. Hecht $\mathrm{E}$ et al (2016) The matrix metalloproteinases 2 and 9 initiate uraemic vascular calcifications. Nephrol Dial Transplant 31(5):789-797

46. Luong TTD et al (2018) Fibulin-3 attenuates phosphate-induced vascular smooth muscle cell calcification by inhibition of oxidative stress. Cell Physiol Biochem 46(4):1305-1316

47. Freise C, Kretzschmar N, Querfeld U (2016) Wnt signaling contributes to vascular calcification by induction of matrix metalloproteinases. BMC Cardiovasc Disord 16(1):185 
48. Sena BF, Figueiredo JL, Aikawa E (2017) Cathepsin S as an inhibitor of cardiovascular inflammation and calcification in chronic kidney disease. Front Cardiovasc Med 4:88

49. Hosaka N et al (2009) Elastin degradation accelerates phosphateinduced mineralization of vascular smooth muscle cells. Calcif Tissue Int 85(6):523-529

50. Roszkowska M et al (2018) Collagen promotes matrix vesiclemediated mineralization by vascular smooth muscle cells. J Inorg Biochem 186:1-9

51. Alesutan I et al (2017) Inhibition of osteo/chondrogenic transformation of vascular smooth muscle cells by $\mathrm{MgCl}_{2}$ via calciumsensing receptor. J Hypertens 35(3):523-532

52. Jover $\mathrm{E}$ et al (2018) Inhibition of enzymes involved in collagen cross-linking reduces vascular smooth muscle cell calcification. FASEB J 32(8):4459-4469

53. Gelse K, Poschl E, Aigner T (2003) Collagens—structure, function, and biosynthesis. Adv Drug Deliv Rev 55(12):1531-1546

54. Proudfoot D et al (2000) Apoptosis regulates human vascular calcification in vitro: evidence for initiation of vascular calcification by apoptotic bodies. Circ Res 87(11):1055-1062

55. Clarke MC et al (2008) Chronic apoptosis of vascular smooth muscle cells accelerates atherosclerosis and promotes calcification and medial degeneration. Circ Res 102(12):1529-1538

56. Ponnusamy A et al (2018) FTI-277 inhibits smooth muscle cell calcification by up-regulating PI3K/Akt signaling and inhibiting apoptosis. PLoS One 13(4):e0196232

57. Waller BF, Clary JD, Rohr T (1997) Nonneoplastic diseases of aorta and pulmonary trunk-part IV. Clin Cardiol 20(11):964-966

58. Steitz SA et al (2001) Smooth muscle cell phenotypic transition associated with calcification: upregulation of Cbfa1 and downregulation of smooth muscle lineage markers. Circ Res 89(12):1147-1154

59. Lang $\mathrm{F}$ et al (2014) Impact of aldosterone on osteoinductive signaling and vascular calcification. Nephron Physiol 128(1-2):40-45

60. Farrington-Rock $\mathrm{C}$ et al (2004) Chondrogenic and adipogenic potential of microvascular pericytes. Circulation 110(15):2226-2232

61. Bostrom K et al (1993) Bone morphogenetic protein expression in human atherosclerotic lesions. J Clin Invest 91(4):1800-1809

62. Schlieper $\mathrm{G}$ et al (2010) Ultrastructural analysis of vascular calcifications in uremia. J Am Soc Nephrol 21(4):689-696

63. Voelkl J et al (2018) Zinc inhibits phosphate-induced vascular calcification through TNFAIP3-mediated suppression of NF-kappaB. J Am Soc Nephrol 29(6):1636-1648. https://doi. org/10.1681/ASN.2017050492

64. Alesutan I et al (2017) Involvement of vascular aldosterone synthase in phosphate-induced osteogenic transformation of vascular smooth muscle cells. Sci Rep 7(1):2059

65. Chen NX, Moe SM (2015) Pathophysiology of vascular calcification. Curr Osteoporos Rep 13(6):372-380

66. Voelkl J et al (2013) Spironolactone ameliorates PIT1-dependent vascular osteoinduction in klotho-hypomorphic mice. J Clin Invest 123(2):812-822

67. Leibrock $\mathrm{CB}$ et al (2015) $\mathrm{NH}_{4} \mathrm{Cl}$ treatment prevents tissue calcification in klotho deficiency. J Am Soc Nephrol 26(10):2423-2433

68. Alesutan I et al (2015) Inhibition of phosphate-induced vascular smooth muscle cell osteo-/chondrogenic signaling and calcification by bafilomycin A1 and methylamine. Kidney Blood Press Res 40(5):490-499

69. Xu Z et al (2012) SOX9 and myocardin counteract each other in regulating vascular smooth muscle cell differentiation. Biochem Biophys Res Commun 422(2):285-290
70. Speer MY et al (2010) Runx2/Cbfa1, but not loss of myocardin, is required for smooth muscle cell lineage reprogramming toward osteochondrogenesis. J Cell Biochem 110(4):935-947

71. Sun $Y$ et al (2012) Smooth muscle cell-specific runx 2 deficiency inhibits vascular calcification. Circ Res 111(5):543-552

72. Lee HL et al (2010) Tumor necrosis factor-alpha increases alkaline phosphatase expression in vascular smooth muscle cells via MSX2 induction. Biochem Biophys Res Commun 391(1):1087-1092

73. Nishio $Y$ et al (2006) Runx2-mediated regulation of the zinc finger Osterix/Sp7 gene. Gene 372:62-70

74. Lau WL, Festing MH, Giachelli CM (2010) Phosphate and vascular calcification: emerging role of the sodium-dependent phosphate co-transporter PiT-1. Thromb Haemost 104(3):464-470

75. Speer MY et al (2009) Smooth muscle cells give rise to osteochondrogenic precursors and chondrocytes in calcifying arteries. Circ Res 104(6):733-741

76. Shanahan CM et al (1999) Medial localization of mineralizationregulating proteins in association with Monckeberg's sclerosis: evidence for smooth muscle cell-mediated vascular calcification. Circulation 100(21):2168-2176

77. Leibrock CB et al (2016) Acetazolamide sensitive tissue calcification and aging of klotho-hypomorphic mice. J Mol Med (Berl) 94(1):95-106

78. Michigami T (2013) Extracellular phosphate as a signaling molecule. Contrib Nephrol 180:14-24

79. Zhang D et al (2017) High phosphate-induced calcification of vascular smooth muscle cells is associated with the TLR4/ NF-kappab signaling pathway. Kidney Blood Press Res 42(6): 1205-1215

80. Li X, Yang HY, Giachelli CM (2006) Role of the sodium-dependent phosphate cotransporter, Pit-1, in vascular smooth muscle cell calcification. Circ Res 98(7):905-912

81. Chavkin NW et al (2015) Phosphate uptake-independent signaling functions of the type III sodium-dependent phosphate transporter, PiT-1, in vascular smooth muscle cells. Exp Cell Res 333(1):39-48

82. Villa-Bellosta R, Levi M, Sorribas V (2009) Vascular smooth muscle cell calcification and SLC20 inorganic phosphate transporters: effects of PDGF, TNF-alpha, and Pi. Pflugers Arch 458(6):1151-1161

83. Villa-Bellosta R et al (2007) Characterization of phosphate transport in rat vascular smooth muscle cells: implications for vascular calcification. Arterioscler Thromb Vasc Biol 27(5):1030-1036

84. Yao L et al (2015) High phosphorus level leads to aortic calcification via beta-catenin in chronic kidney disease. Am J Nephrol 41(1):28-36

85. Wu Y et al (2016) Indoxyl sulfate promotes vascular smooth muscle cell calcification via the JNK/Pit-1 pathway. Ren Fail 38(10): 1702-1710

86. Masuda $\mathrm{M}$ et al (2016) Activating transcription factor-4 promotes mineralization in vascular smooth muscle cells. JCI Insight 1(18):e88646

87. Hortells L et al (2017) Identifying early pathogenic events during vascular calcification in uremic rats. Kidney Int 92(6):1384-1394

88. Crouthamel MH et al (2013) Sodium-dependent phosphate cotransporters and phosphate-induced calcification of vascular smooth muscle cells: redundant roles for PiT-1 and PiT-2. Arterioscler Thromb Vasc Biol 33(11):2625-2632

89. Yamada $\mathrm{S}$ et al (2018) PiT-2, a type III sodium-dependent phosphate transporter, protects against vascular calcification in mice with chronic kidney disease fed a high-phosphate diet. Kidney Int 94(4):716-727. https://doi.org/10.1016/j.kint.2018.05.015

90. Makarovic S et al (2015) Osteoprotegerin and vascular calcification: clinical and prognostic relevance. Coll Antropol 39(2):461-468 
91. Zhao G et al (2012) Activation of nuclear factor-kappa B accelerates vascular calcification by inhibiting ankylosis protein homolog expression. Kidney Int 82(1):34-44

92. Yoshida T et al (2017) Smooth muscle-selective nuclear factorkappaB inhibition reduces phosphate-induced arterial medial calcification in mice with chronic kidney disease. J Am Heart Assoc 6(11):e007248

93. Voelkl J et al (2018) SGK1 induces vascular smooth muscle cell calcification through NF-kB signaling. J Clin Invest 128(7):3024-3040. https://doi.org/10.1172/JCI96477

94. Lang F, Voelkl J (2013) Therapeutic potential of serum and glucocorticoid inducible kinase inhibition. Expert Opin Investig Drugs 22(6):701-714

95. Lang F, Stournaras C, Alesutan I (2014) Regulation of transport across cell membranes by the serum- and glucocorticoid-inducible kinase SGK1. Mol Membr Biol 31(1):29-36

96. Voelkl J et al (2015) SGK1-sensitive regulation of cyclin-dependent kinase inhibitor 1B (p27) in cardiomyocyte hypertrophy. Cell Physiol Biochem 37(2):603-614

97. Voelkl J et al (2013) Sgk1-dependent stimulation of cardiac $\mathrm{Na}^{+} /$ $\mathrm{H}^{+}$exchanger Nhe1 by dexamethasone. Cell Physiol Biochem 32(1):25-38

98. Voelk1 J et al (2012) Sgk1 sensitivity of $\mathrm{Na}(+) / \mathrm{H}(+)$ exchanger activity and cardiac remodeling following pressure overload. Basic Res Cardiol 107(2):236

99. Tai DJ et al (2009) SGK1 phosphorylation of IkappaB Kinase alpha and p300 Up-regulates NF-kappaB activity and increases $\mathrm{N}$-methyl-D-aspartate receptor NR2A and NR2B expression. J Biol Chem 284(7):4073-4089

100. Cui L et al (2016) Effects of extracellular acid stimulation on rat vascular smooth muscle cell in Gas6/Axl or PI3K/Akt signaling pathway. Clin Exp Hypertens 38(5):451-456

101. Deng $L$ et al (2015) Inhibition of FOXO1/3 promotes vascular calcification. Arterioscler Thromb Vasc Biol 35(1):175-183

102. Konoplyannikov M, Nurminskaya M (2014) New therapeutic approaches to arterial calcification via inhibition of transglutaminase and beta-catenin signaling. Curr Pharm Des 20(37):5811-5820

103. Wu D, Pan W (2010) GSK3: a multifaceted kinase in Wnt signaling. Trends Biochem Sci 35(3):161-168

104. Tuffaha R et al (2018) Role of PKB/SGK-dependent phosphorylation of GSK-3alpha/beta in vascular calcification during cholecalciferol overload in mice. Biochem Biophys Res Commun 503(3):2068-2074

105. Shao JS et al (2005) Msx2 promotes cardiovascular calcification by activating paracrine Wnt signals. J Clin Invest 115(5):1210-1220

106. Cai T et al (2016) WNT/beta-catenin signaling promotes VSMCs to osteogenic transdifferentiation and calcification through directly modulating Runx 2 gene expression. Exp Cell Res 345(2):206-217

107. Zhang $\mathrm{H}$ et al (2018) Indoxyl sulfate accelerates vascular smooth muscle cell calcification via microRNA-29b dependent regulation of $\mathrm{Wnt} /$ beta-catenin signaling. Toxicol Lett 284:29-36

108. Martinez-Moreno JM et al (2012) In vascular smooth muscle cells paricalcitol prevents phosphate-induced Wnt/beta-catenin activation. Am J Physiol Renal Physiol 303(8):F1136-F1144

109. Bisson SK, Ung RV, Mac-Way F (2018) Role of the Wnt/betacatenin pathway in renal osteodystrophy. Int J Endocrinol 2018:5893514

110. de Oca AM et al (2014) Magnesium inhibits Wnt/beta-catenin activity and reverses the osteogenic transformation of vascular smooth muscle cells. PLoS One 9(2):e89525

111. Tian BY et al (2018) Specific knockdown of WNT8b expression protects against phosphate-induced calcification in vascular smooth muscle cells by inhibiting the Wnt-betacatenin signaling pathway. J Cell Physiol 234(4):3469-3477. https://doi.org/10.1002/jcp.26827

112. Deng D et al (2016) Secreted frizzled-related protein 5 attenuates high phosphate-induced calcification in vascular smooth muscle cells by inhibiting the Wnt/ss-catenin pathway. Calcif Tissue Int 99(1):66-75

113. Fang $\mathrm{Y}$ et al (2014) CKD-induced wingless/integration1 inhibitors and phosphorus cause the CKD-mineral and bone disorder. J Am Soc Nephrol 25(8):1760-1773

114. Meng $Z$ et al (2017) A20 ameliorates intracerebral hemorrhage-induced inflammatory injury by regulating TRAF6 polyubiquitination. J Immunol 198(2):820-831

115. Mary A et al (2015) Calcitriol prevents in vitro vascular smooth muscle cell mineralization by regulating calciumsensing receptor expression. Endocrinology 156(6):1965-1974

116. Molostvov G et al (2015) Arterial expression of the calciumsensing receptor is maintained by physiological pulsation and protects against calcification. PLoS One 10(10):e0138833

117. Diaz-Soto G et al (2016) The calcium-sensing receptor in health and disease. Int Rev Cell Mol Biol 327:321-369

118. Henaut L et al (2014) Calcimimetics increase CaSR expression and reduce mineralization in vascular smooth muscle cells: mechanisms of action. Cardiovasc Res 101(2):256-265

119. Lang F et al (2018) Therapeutic interference with vascular calcification-lessons from klotho-hypomorphic mice and beyond. Front Endocrinol (Lausanne) 9:207

120. Henaut L, Massy ZA (2018) Magnesium as a calcification inhibitor. Adv Chronic Kidney Dis 25(3):281-290

121. Houben $\mathrm{E}$ et al (2016) The influence of phosphate, calcium and magnesium on matrix Gla-protein and vascular calcification: a systematic review. G Ital Nefrol 33(6):1724-5590

122. Ter Braake AD et al (2018) Magnesium prevents vascular calcification in vitro by inhibition of hydroxyapatite crystal formation. Sci Rep 8(1):2069

123. Zhao $Y$ et al (2015) Mammalian target of rapamycin signaling inhibition ameliorates vascular calcification via Klotho upregulation. Kidney Int 88(4):711-721

124. Lim K et al (2012) Vascular Klotho deficiency potentiates the development of human artery calcification and mediates resistance to fibroblast growth factor 23. Circulation 125(18):2243-2255

125. Hu MC et al (2011) Klotho deficiency causes vascular calcification in chronic kidney disease. J Am Soc Nephrol 22(1):124-136

126. Scialla JJ et al (2013) Fibroblast growth factor 23 is not associated with and does not induce arterial calcification. Kidney Int 83(6): 1159-1168

127. Saito $\mathrm{Y}$ et al (2017) Suppression of Wnt signaling and osteogenic changes in vascular smooth muscle cells by eicosapentaenoic acid. Nutrients 9(8):858

128. Chen $\mathrm{T}$ et al (2015) The role and mechanism of alpha-Klotho in the calcification of rat aortic vascular smooth muscle cells. Biomed Res Int 2015:194362

129. Nakahara $T$ et al (2016) Fibroblast growth factor 23 inhibits osteoblastic gene expression and induces osteoprotegerin in vascular smooth muscle cells. Atherosclerosis 253:102-110

130. Jimbo R et al (2014) Fibroblast growth factor 23 accelerates phosphate-induced vascular calcification in the absence of Klotho deficiency. Kidney Int 85(5):1103-1111

131. Giachelli CM (2009) The emerging role of phosphate in vascular calcification. Kidney Int 75(9):890-897

132. Benz K et al (2017) Vascular inflammation and media calcification are already present in early stages of chronic kidney disease. Cardiovasc Pathol 27:57-67 
133. Schelski N et al (2019) SGK1-dependent stimulation of vascular smooth muscle cell osteo-/chondrogenic transdifferentiation by interleukin-18. Pflugers Arch. https://doi.org/10.1007/s0042 4-019-02256-5

134. Li X, Yang HY, Giachelli CM (2008) BMP-2 promotes phosphate uptake, phenotypic modulation, and calcification of human vascular smooth muscle cells. Atherosclerosis 199(2):271-277

135. Yamada S et al (2014) Phosphate overload directly induces systemic inflammation and malnutrition as well as vascular calcification in uremia. Am J Physiol Renal Physiol 306(12):F1418-F1428

136. Ewence AE et al (2008) Calcium phosphate crystals induce cell death in human vascular smooth muscle cells: a potential mechanism in atherosclerotic plaque destabilization. Circ Res 103(5):e28-e34

137. Wen $\mathrm{C}$ et al (2013) Nalp3 inflammasome is activated and required for vascular smooth muscle cell calcification. Int J Cardiol 168(3):2242-2247

138. Agharazii $\mathrm{M}$ et al (2015) Inflammatory cytokines and reactive oxygen species as mediators of chronic kidney disease-related vascular calcification. Am J Hypertens 28(6):746-755

139. McGeough MD et al (2017) TNF regulates transcription of NLRP3 inflammasome components and inflammatory molecules in cryopyrinopathies. J Clin Invest 127(12):4488-4497

140. Panizo $S$ et al (2009) RANKL increases vascular smooth muscle cell calcification through a RANK-BMP4-dependent pathway. Circ Res 104(9):1041-1048

141. Zhang $\mathrm{K}$ et al (2017) Interleukin-18 enhances vascular calcification and osteogenic differentiation of vascular smooth muscle cells through TRPM7 activation. Arterioscler Thromb Vasc Biol 37(10):1933-1943

142. Borst $\mathrm{O}$ et al (2015) Pivotal role of serum- and glucocorticoidinducible kinase 1 in vascular inflammation and atherogenesis. Arterioscler Thromb Vasc Biol 35(3):547-557

143. Ma B, Hottiger MO (2016) Crosstalk between Wnt/beta-catenin and NF-kappaB signaling pathway during inflammation. Front Immunol 7:378

144. Al-Aly Z et al (2007) Aortic Msx2-Wnt calcification cascade is regulated by TNF-alpha-dependent signals in diabetic Ldlr-/mice. Arterioscler Thromb Vasc Biol 27(12):2589-2596

145. Rong S et al (2014) Vascular calcification in chronic kidney disease is induced by bone morphogenetic protein- 2 via a mechanism involving the Wnt/beta-catenin pathway. Cell Physiol Biochem 34(6):2049-2060

146. Derwall $\mathrm{M}$ et al (2012) Inhibition of bone morphogenetic protein signaling reduces vascular calcification and atherosclerosis. Arterioscler Thromb Vasc Biol 32(3):613-622

147. Shimizu T et al (2011) Notch signaling pathway enhances bone morphogenetic protein 2 (BMP2) responsiveness of Msx2 gene to induce osteogenic differentiation and mineralization of vascular smooth muscle cells. J Biol Chem 286(21):19138-19148

148. Liberman $\mathrm{M}$ et al (2011) Bone morphogenetic protein-2 activates NADPH oxidase to increase endoplasmic reticulum stress and human coronary artery smooth muscle cell calcification. Biochem Biophys Res Commun 413(3):436-441

149. Callegari A et al (2014) Increased calcification in osteoprotegerin-deficient smooth muscle cells: dependence on receptor activator of NF-kappaB ligand and interleukin 6. J Vasc Res 51(2):118-131

150. Deuell KA et al (2012) RANKL enhances macrophage paracrine pro-calcific activity in high phosphate-treated smooth muscle cells: dependence on IL-6 and TNF-alpha. J Vasc Res 49(6):510-521

151. Henaut L, Massy ZA (2018) New insights into the key role of interleukin 6 in vascular calcification of chronic kidney disease.
Nephrol Dial Transplant 33(4):543-548. https://doi.org/10.1093/ ndt/gfx379

152. Sun M et al (2017) Endogenous bone morphogenetic protein 2 plays a role in vascular smooth muscle cell calcification induced by interleukin 6 in vitro. Int J Immunopathol Pharmacol 30(3):227-237

153. Abedin $\mathrm{M}$ et al (2006) N-3 fatty acids inhibit vascular calcification via the $\mathrm{p} 38$-mitogen-activated protein kinase and peroxisome proliferator-activated receptor-gamma pathways. Circ Res 98(6):727-729

154. Lin L et al (2016) MiR-135a suppresses calcification in senescent VSMCs by regulating KLF4/STAT3 pathway. Curr Vasc Pharmacol 14(2):211-218

155. Kanno $Y$ et al (2008) Nitric oxide regulates vascular calcification by interfering with TGF- signaling. Cardiovasc Res 77(1):221-230

156. Caron MM et al (2013) Osmolarity determines the in vitro chondrogenic differentiation capacity of progenitor cells via nuclear factor of activated T-cells 5. Bone 53(1):94-102

157. Wang $\mathrm{N}$ et al (2013) Role of TGF-betal in production of fibronectin in vascular smooth muscle cells cultured under highphosphate conditions. J Nephrol 26(1):213-218

158. He Y, Hara H, Nunez G (2016) Mechanism and regulation of NLRP3 inflammasome activation. Trends Biochem Sci 41(12):1012-1021

159. Weinert $\mathrm{S}$ et al (2013) The lysosomal transfer of LDL/cholesterol from macrophages into vascular smooth muscle cells induces their phenotypic alteration. Cardiovasc Res 97(3):544-552

160. Basque $\mathrm{J}$ et al (2008) Lysosomotropic drugs inhibit maturation of transforming growth factor-beta. Can J Physiol Pharmacol 86(9):606-612

161. Aghagolzadeh P et al (2016) Calcification of vascular smooth muscle cells is induced by secondary calciprotein particles and enhanced by tumor necrosis factor-alpha. Atherosclerosis 251:404-414

162. Aghagolzadeh $P$ et al (2017) Hydrogen sulfide attenuates calcification of vascular smooth muscle cells via KEAP1/NRF2/NQO1 activation. Atherosclerosis 265:78-86

163. Bostom A et al (2018) Serum calcification propensity and fetuinA: biomarkers of cardiovascular disease in kidney transplant recipients. Am J Nephrol 48(1):21-31

164. Lorenz $\mathrm{G}$ et al (2017) Worsening calcification propensity precedes all-cause and cardiovascular mortality in haemodialyzed patients. Sci Rep 7(1): 13368

165. Smith ER et al (2014) Serum calcification propensity predicts all-cause mortality in predialysis CKD. J Am Soc Nephrol 25(2):339-348

166. Liakopoulos V et al (2017) Oxidative stress in hemodialysis patients: a review of the literature. Oxid Med Cell Longev 2017:3081856

167. Zhao MM et al (2011) Mitochondrial reactive oxygen species promote p65 nuclear translocation mediating high-phosphateinduced vascular calcification in vitro and in vivo. Kidney Int 79(10):1071-1079

168. Beloqui $O$ et al (2017) Increased phagocytic NADPH oxidase activity associates with coronary artery calcification in asymptomatic men. Free Radic Res 51(4):389-396

169. Byon $\mathrm{CH}$ et al (2008) Oxidative stress induces vascular calcification through modulation of the osteogenic transcription factor Runx2 by AKT signaling. J Biol Chem 283(22):15319-15327

170. Nguyen TT et al (2016) Intracellular alkalinization by phosphate uptake via type III sodium-phosphate cotransporter participates in high-phosphate-induced mitochondrial oxidative stress and defective insulin secretion. FASEB J 30(12):3979-3988

171. Blanc A, Pandey NR, Srivastava AK (2004) Distinct roles of $\mathrm{Ca}^{2+}$, calmodulin, and protein kinase $\mathrm{C}$ in $\mathrm{H}_{2} \mathrm{O}_{2}$-induced 
activation of ERK1/2, p38 MAPK, and protein kinase B signaling in vascular smooth muscle cells. Antioxid Redox Signal $6(2): 353-366$

172. Liu H et al (2014) Selenium suppresses oxidative-stressenhanced vascular smooth muscle cell calcification by inhibiting the activation of the PI3K/AKT and ERK signaling pathways and endoplasmic reticulum stress. J Biol Inorg Chem 19(3):375-388

173. Yang $\mathrm{Y}$ et al (2018) AKT-independent activation of p38 MAP kinase promotes vascular calcification. Redox Biol 16:97-103

174. Rajamaki K et al (2016) p38delta MAPK: a novel regulator of NLRP3 inflammasome activation with increased expression in coronary atherogenesis. Arterioscler Thromb Vasc Biol 36(9):1937-1946

175. Vermeulen L et al (2003) Transcriptional activation of the NFkappaB p65 subunit by mitogen- and stress-activated protein kinase-1 (MSK1). EMBO J 22(6):1313-1324

176. Pietrowski E et al (2011) Pro-inflammatory effects of interleukin$17 \mathrm{~A}$ on vascular smooth muscle cells involve $\mathrm{NAD}(\mathrm{P}) \mathrm{H}$ - oxidase derived reactive oxygen species. J Vasc Res 48(1):52-58

177. Mizobuchi M, Towler D, Slatopolsky E (2009) Vascular calcification: the killer of patients with chronic kidney disease. J Am Soc Nephrol 20(7):1453-1464

178. Gomez C et al (2015) Oxidative stress induces early-onset apoptosis of vascular smooth muscle cells and neointima formation in response to injury. Biosci Rep 35(4):e00227

179. Yamada $\mathrm{S}$ et al (2012) The antioxidant tempol ameliorates arterial medial calcification in uremic rats: important role of oxidative stress in the pathogenesis of vascular calcification in chronic kidney disease. J Bone Miner Res 27(2):474-485

180. Boehme B et al (2018) Role of cytosolic serine hydroxymethyl transferase 1 (SHMT1) in phosphate-induced vascular smooth muscle cell calcification. Kidney Blood Press Res 43(4):1212-1221

181. Passauer J, Pistrosch F, Bussemaker E (2005) Nitric oxide in chronic renal failure. Kidney Int 67(5):1665-1667

182. Qiu C et al (2017) Vitamin K2 inhibits rat vascular smooth muscle cell calcification by restoring the Gas6/Axl/Akt anti-apoptotic pathway. Mol Cell Biochem 433(1-2):149-159

183. Son BK et al (2007) Gas6/Axl-PI3K/Akt pathway plays a central role in the effect of statins on inorganic phosphate-induced calcification of vascular smooth muscle cells. Eur J Pharmacol $556(1-3): 1-8$

184. Son BK et al (2006) Statins protect human aortic smooth muscle cells from inorganic phosphate-induced calcification by restoring Gas6-Axl survival pathway. Circ Res 98(8):1024-1031

185. Ciceri $P$ et al (2016) Iron citrate reduces high phosphate-induced vascular calcification by inhibiting apoptosis. Atherosclerosis 254:93-101

186. Nanao-Hamai M et al (2016) Protective effects of estrogen against vascular calcification via estrogen receptor alpha-dependent growth arrest-specific gene 6 transactivation. Biochem Biophys Res Commun 480(3):429-435

187. Son BK et al (2010) Androgen receptor-dependent transactivation of growth arrest-specific gene 6 mediates inhibitory effects of testosterone on vascular calcification. J Biol Chem 285(10):7537-7544

188. Kim H et al (2012) alpha-Lipoic acid attenuates vascular calcification via reversal of mitochondrial function and restoration of Gas6/Axl/Akt survival pathway. J Cell Mol Med 16(2):273-286

189. Ma WQ et al (2019) Restoring mitochondrial biogenesis with metformin attenuates beta-GP-induced phenotypic transformation of VSMCs into an osteogenic phenotype via inhibition of PDK4/oxidative stress-mediated apoptosis. Mol Cell Endocrinol 479:39-53

190. Son BK et al (2008) Adiponectin antagonizes stimulatory effect of tumor necrosis factor-alpha on vascular smooth muscle cell calcification: regulation of growth arrest-specific gene 6-mediated survival pathway by adenosine 5 '-monophosphate-activated protein kinase. Endocrinology 149(4):1646-1653

191. Xu M et al (2017) Ghrelin improves vascular autophagy in rats with vascular calcification. Life Sci 179:23-29

192. Wu SS et al (2015) The role of epigenetics in arterial calcification. Biomed Res Int 2015:320849

193. Nanoudis S et al (2017) The role of MicroRNAs in arterial stiffness and arterial calcification. An update and review of the literature. Front Genet 8:209

194. de Oca AM et al (2010) High-phosphate-induced calcification is related to SM22alpha promoter methylation in vascular smooth muscle cells. J Bone Miner Res 25(9):1996-2005

195. Zhou $\mathrm{S}$ et al (2017) CDKN2B methylation and aortic arch calcification in patients with ischemic stroke. J Atheroscler Thromb 24(6):609-620

196. Azechi T et al (2014) 5-aza-2'-Deoxycytidine, a DNA methyltransferase inhibitor, facilitates the inorganic phosphorusinduced mineralization of vascular smooth muscle cells. J Atheroscler Thromb 21(5):463-476

197. Kwon DH, Kim YK, Kook H (2017) New aspects of vascular calcification: histone deacetylases and beyond. J Korean Med Sci 32(11):1738-1748

198. Leopold JA (2014) MicroRNAs regulate vascular medial calcification. Cells 3(4):963-980

199. Alkagiet S, Tziomalos K (2017) Vascular calcification: the role of microRNAs. Biomol Concepts 8(2):119-123

200. Sudo R et al (2015) MiR-29-mediated elastin down-regulation contributes to inorganic phosphorus-induced osteoblastic differentiation in vascular smooth muscle cells. Genes Cells 20(12):1077-1087

201. Badi I et al (2018) miR-34a promotes vascular smooth muscle cell calcification by downregulating SIRT1 (sirtuin 1) and Axl (AXL receptor tyrosine kinase). Arterioscler Thromb Vasc Biol 38(9):2079-2090

202. Jiang W et al (2017) The involvement of miR-29b-3p in arterial calcification by targeting matrix metalloproteinase- 2 . Biomed Res Int 2017:6713606

203. Duan X et al (2009) Endoplasmic reticulum stress-mediated apoptosis is activated in vascular calcification. Biochem Biophys Res Commun 387(4):694-699

204. Liu J et al (2017) MicroRNA-32 promotes calcification in vascular smooth muscle cells: implications as a novel marker for coronary artery calcification. PLoS One 12(3):e0174138

205. Song R et al (2017) An epigenetic regulatory loop controls proosteogenic activation by TGF-beta1 or bone morphogenetic protein 2 in human aortic valve interstitial cells. J Biol Chem 292(21):8657-8666

206. Shroff R (2013) Phosphate is a vascular toxin. Pediatr Nephrol 28(4):583-593

207. Kroenke $\mathrm{CH}$ et al (2012) Telomerase, telomere length, and coronary artery calcium in black and white men in the CARDIA study. Atherosclerosis 220(2):506-512

208. Liu Y et al (2013) Prelamin A accelerates vascular calcification via activation of the DNA damage response and senescenceassociated secretory phenotype in vascular smooth muscle cells. Circ Res 112(10):e99-e109

209. Burton DG et al (2009) Microarray analysis of senescent vascular smooth muscle cells: a link to atherosclerosis and vascular calcification. Exp Gerontol 44(10):659-665

210. Kovacic JC et al (2011) Cellular senescence, vascular disease, and aging: part 2 of a 2-part review: clinical vascular disease in the elderly. Circulation 123(17):1900-1910

211. Takemura A et al (2011) Sirtuin 1 retards hyperphosphatemiainduced calcification of vascular smooth muscle cells. Arterioscler Thromb Vasc Biol 31(9):2054-2062 
212. Gorenne I et al (2006) Vascular smooth muscle cell senescence in atherosclerosis. Cardiovasc Res 72(1):9-17

213. Zhang $P$ et al (2016) Resveratrol ameliorated vascular calcification by regulating Sirt-1 and Nrf2. Transplant Proc 48(10):3378-3386

214. Dai XY et al (2013) Phosphate-induced autophagy counteracts vascular calcification by reducing matrix vesicle release. Kidney Int 83(6):1042-1051

215. Shanahan CM (2013) Autophagy and matrix vesicles: new partners in vascular calcification. Kidney Int 83(6):984-986
216. Peng YQ et al (2017) Oestrogen inhibits arterial calcification by promoting autophagy. Sci Rep 7(1):3549

Publisher's Note Springer Nature remains neutral with regard to jurisdictional claims in published maps and institutional affiliations. 